\title{
PEP II News and Plans
}

The major gap in proxy data records from the middle section of the PEP II transect is now being addressed by an expansion of research work in the south east Asian region. Most of this is a result of the development of new collaborative projects on the study of tree rings, corals, ocean cores and lake and peatland systems in Cambodia, Indonesia, Singapore and Thailand. University researchers from Australia (including Barbetti, Boyd, Gagan, Kershaw), Indonesia (Hantoro), The Netherlands (van Dam) and USA (Cook) are some of those who are leading this work. There continues to be an expansion of the cooperative work between Chinese scientists in Beijing and $\mathrm{Xi}^{\prime}$ an with Australians in Melbourne and Perth on sites from China and Australia. This is allowing groups from both regions to undertake joint research and multiproxy analyses, and, as a result, study of the history of dust spread will expand in Australia and human impact studies will expand in China. These kinds of cooperative ventures and sharing of expertise are one of the principle aims of the IGBP program.

In this regard the PEP II leaders are aiming to develop a list of facilities which are available across the region. Recently funding has been obtained to develop a dedicated ${ }^{14} \mathrm{C}$ AMS facility at Lucas Heights in Sydney for all Australian and some New Zealand university researchers. In addition a state-ofart mass spectrometry system for stable isotopes will be developed on two campuses in Perth as a result of funding from the Australian Research Council and the Government of Western Australia. Both of the facilities will be available for collaborative research projects across the region.

In 1999 three PAGES related projects were approved by the Chinese Ministry of Science and Technology. The projects are oriented to study palaeoclimates of the Yellow River Basin, Holocene changes in the dry lands of China and palaeoclimates in the Tibetan Plateau region. These are funding new drilling projects for ice cores and lake sediments, and providing some of the financial support to bring researchers from other countries to China.

One highlight of research in the PEP II transect comes from a pollen diagram recently completed by Hwee Yen and David Taylor from Singapore. It provides the first late Pleistocene and Holocene record from this country and it has a fascinating story of the impact of sealevel and climate variability on vegetation near the Equator from the region.

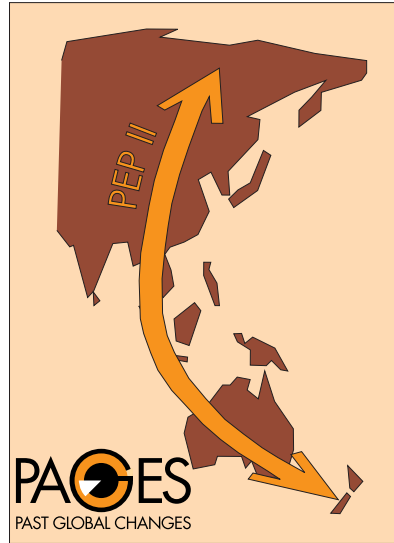

ongoing research within the U.S. PARCS/PALE program is well positioned for PEP II-PEP I comparisons across Beringia and the north Pacific, an exercise that would provide integration across a complex area of great contrasts in quaternary records.

In the year 2001 a PEP II meeting will be held to a fire history that shows a definite increase in charcoal input from around 5000 BP. This may be a result of intensification of human impact in the Singapore region, and/ or the development of ENSO patterns. The latter leads to periodic drought and increased burning in the region, as has happened in the intense negative SOI events of the last few decades.

Future plans need to expand the notion of PEP II to include areas to the north of Japan beyond monsoonal influence. Ongoing work throughout Siberia, Northeastern Russia and the Russian far east must be included to extend the transect into the arctic and subarctic regions. Existing programs in tree ring studies and lacustrine records, especially, could be easily integrated with marine based studies of the north Pacific, the Sea of Okhotsk, and the Bering and Chukchi seas. Maturing programs now studying lake records from Mongolia to Lake Baikal to Elgygytgyn could prepare for syntheses of stream II while integrating across shorter records relevant to millennial to decadal records of the past 20,000 years as a focus in stream 1. By broadening the scope of PEP II to include the Siberian subarctic and Arctic portion of the records, changes in the influence of the monsoon vs the westerlies can be properly evaluated at new spatial and temporal scales. Moreover, this will prepare PEP II for integrating the northern end of all of the PEP transects within the scope of PAGES CAPE/ICAPP/ QUEEN, thereby evaluating the role of the arctic system in global environmental change. Thematic integration comparing PEP III to PEP II across the Eurasian arctic is especially relevant to assessing the distal influence of the North Atlantic heat pump into arctic regions as envisioned by programs like IMAGES, QUEEEN, and the US-PARCS. Likewise, draw together a synthesis of palaeoclimate studies across the region. Specifics will be developed later this year, however the meeting will be held in Singapore. The aim will be to develop detailed histories of the Northern and Southern Hemisphere westerlies, cross-Equator and sea-level links in Tropical and Monsoon systems, the history of ENSO from the perspective of the western Pacific region, a comparison of Stage 5e and mid-Holocene climates from the region, and an assessment of the new model experiments which need to be done for the region.

Finally, on an organizational note, Liu Tungsheng has indicated his wish to retire from his position as co-Leader of PEP II. To ensure that both ends of the Austral-Asian transect continue to be represented in the running of PEP, Guo Zhengtang has been appointed as the new co-leader, together with John Dodson. Guo received his $\mathrm{PhD}$ from the University of Paris VI in 1990 and specializes in Quaternary Geology and Paleoclimatology. He is now a Research Professor at the Institute of Geology in Beijing. Since 1996, he has been a member of the PAGES Scientific Steering Committee and has been assisting Liu Tungsheng in coordinating PEP II.

\section{John DOdson}

Department of Geography, University of Western Australia, Perth, Australia johnd@geog.uwa.edu.au

\section{Guo Zhengtang}

Institute of Geology and Geophysics, Chinese Academy of Sciences, Beijing, China

ztguo@public.east.cn.net

\section{Julie Brigham-Grette}

Dept. of Geosciences, Univ. of Massachusetts, Amherst, MA, USA

brigham-grette@geo.umass.edu 